Infection

\section{Health protection and a new strategy for combating infection in children}

\section{E G Davies, M Sharland, A Nicoll}

A unique opportunity to develop world class infection and health protection services for children

T he Chief Medical Officer (CMO) for England has recently published a strategy for health protection (see box for definition).' The prevention, diagnosis, and management of infection forms a large part of this but the new Health Protection Agency (HPA), which will become active in April 2003, will also deal with emergency planning and environmental threats to human health as there are many overlaps in the approaches to dealing with infections, and chemical and radiological threats. ${ }^{1}$ This initiative has important implications for the way in which paediatricians will work to protect children from all such threats. In combination with the $\mathrm{Na}$ tional Service Framework (NSF) for Children, ${ }^{2}$ it offers the opportunity for developing networks of care which will potentially provide a high quality infection diagnosis and treatment service for all children.

\section{INCREASING THREATS FROM INFECTION, AND CHEMICAL AND OTHER AGENTS}

Infections are causing increasing problems in public health and clinical care. The rising toll of HIV and other sexually transmitted infections, ${ }^{3}$ mounting numbers of cases of tuberculosis (particularly in London), ${ }^{4}$ health care associated infections and antibiotic resistant pathogens in hospitals and the community, and the continuing worries over immunisation uptake ${ }^{6}$ are but a few. ${ }^{1}$ Children are particularly vulnerable to exposure to environmental toxic agents in utero and in early life. Chemical spills and natural disasters have revealed gaps in civil protection in many countries and there are increasing concerns over terrorism, including the covert deliberate release of biological and chemical agents. ${ }^{18-11}$ The strategy addresses these issues for England.

\section{Health protection-definition}

- The communicable disease function

- Protection against non-communicable environmental hazards

- Emergency planning and response

\section{A HEALTH PROTECTION AGENCY}

A new Agency will be developed by combining three current non-departmental public bodies (the Public Health Laboratory Service, the Centre for Applied Microbiological Research, and the National Radiological Protection Board) with personnel currently delivering local protection services. These include consultants in communicable disease control, chemical incident response services, toxicology services, and health emergency planners. Equally however, most aspects of local health protection will continue to rely on the National Health Service, for example in delivering immunisation services and infection control in trusts. Local health protection agreements and partnerships will contribute to delivering health protection in England. ${ }^{1}$ The partnerships will have to be comprised of acute trusts (including paediatrics and microbiology), local health protection units of the HPA, local authorities, and networked groups of primary care trusts (PCTs). The Strategy puts the protection of the public's health in the centre of government strategy. The UK's devolved administrations (Northern Ireland, Scotland, and Wales) are now deciding how they will relate to the Agency, and the children's NSF. Wales, for example, will have its own public health service.

\section{AN INFECTION STRATEGY FOR CHILDREN}

Protecting children against infectious disease is given particular priority in the $\mathrm{CMO}^{\prime}$ s strategy. ${ }^{1}$ This will be reflected in the National Service Framework for Children where strengthened preventive services and clinical care for children with infections are to be highlighted. It recognises that the burden of infectious disease is greater in children than other age groups, ${ }^{12}$ and that there are special issues relating to infection in children (see box). A number of protective interventions are under utilised in the UK. rates have been static in recent years in England, in contrast to trends in some other countries, including other parts of the UK. ${ }^{13}$ One example is breast feeding, where

\section{Immunisation}

Delivering high quality vaccine services is central to the CMO's strategy. ${ }^{1}$ In introducing conjugate meningococcal $\mathrm{C}$ vaccines (1998-99) the UK has led the world. ${ }^{14}$ However other available vaccines have yet to be evaluated for cost effectiveness and introduced. Notable are those protecting against invasive pneumococcal disease and varicella. Vaccine safety is an ever increasing concern for parents, and long term investment needs to be made in mechanisms for quickly assessing reports of credible adverse events. ${ }^{15}{ }^{16}$ Considerable progress can be made in restoring confidence, but the level of action needs to focus at the local and personal level, with confident discussions between parents and practitioners. A long term strategy has begun, training relevant professionals in every primary care and acute trust, drawing on the "training of trainers" approach, which was successfully employed in some localities to deal with concerns over whooping cough containing vaccines in the 1980s.

The changes in England's health services under the Shifting the Balance of Power initiative are posing difficulties. ${ }^{18}$ The abolition of district health authorities is the most fundamental reform since the abolition of area health authorities and medical officers (1974) which left local immunisation services without leadership and clarity over responsibility when facing whooping cough vaccine scares. ${ }^{19}$ Immunising children will remain a responsibility of PCTs but in England there is confusion as to whether this applies to children registered with PCTs or all children living within their ill defined boundaries. It is also unclear how the role of the district immunisation coordinators (some of

Children and infection-special issues

- The positive impact of breast feeding

- Immunisation programmes and the need to respond confidently to concerns around safety

- The prevention and management of infection transmitted from mother to child or acquired during the newborn period

- The detection and optimal management of serious, uncommon, and imported infections

- The care and protection of children with impaired immune systems

- The appropriate use of antibiotics in children in an era of increasing antibiotic resistance

- Preparing for adolescence and the risks of sexually transmitted infections and blood borne viruses 
whom are community paediatricians) will be preserved as paediatricians move into either PCTs or acute trusts. Immunisation of special groups such as the immunocompromised poses new problems for health professionals. A recently published best practice statement offers practical guidance but highlights the lack of a good evidence base and the need for further research. ${ }^{20}$

\section{Preventing perinatal infections}

Antenatal screening for infections (hepatitis B, HIV, rubella susceptibility, and syphilis) is highly effective, ${ }^{21-23}$ but is currently suboptimal in parts of the UK. ${ }^{24}$ Proposed standards for antenatal screening have appeared on the National Screening Committee website and once agreed, will need to be met by primary care and acute trusts. However, the problems mentioned above concerning immunisation (lack of clarity over which patients PCTs are responsible for) apply equally for screening. ${ }^{18}$ A practical strategy for prevention of early onset group B streptococcal infection in newborns is yet to be agreed and this is also a priority. Such a strategy has been employed in the United States for some years with a resulting fall in incidence of this high mortality disease. ${ }^{25}$

\section{Optimal management of unusual and imported infections}

As rates of serious imported infections rise (gastrointestinal infections, tuberculosis, HIV, and malaria) paediatricians are increasingly liable to encounter these. ${ }^{126} 27$ These infections may not be diagnosed and treated optimally. Early recognition and optimal management of imported infections, and indigenous serious infections (such as meningococcal disease) significantly improve outcomes. ${ }^{28}$

Numbers of neonates and children especially vulnerable to infection because of impaired immunity are increasing. Among neonates this is because of better survival of very low birth weight babies. In older children it results from the increasing intensity of chemotherapeutic protocols for malignant disease, use of immune modulating and immunosuppressive treatments for nonmalignant disorders, better recognition of primary immune deficiency disorders, improved survival of children with HIV, and increasing numbers of children receiving organ and bone marrow transplantation. These children are susceptible to infection with common organisms, which may behave atypically, or to unusual organisms, and in both these circumstances antimicrobial resistance is an increasing problem. Professional responses to these issues are crucial and need to be reflected in training, updating, and staffing in general and specialist paediatrics.

\section{Sexual health}

UK children are entering adolescence earlier than ever and need to be prepared for the growing risks of sexually transmitted infections, and blood borne viruses acquired through drug misuse. ${ }^{129-30}$ Here there is substantial work to be done in prevention and recognition of sexually transmitted infections and other aspects of sexual ill health. With notable exceptions UK paediatricians have taken a low profile in this field and leadership will have to be achieved from the areas of primary care, public health, and genitourinary medicine within the national Sexual Health and HIV Strategy. ${ }^{28}$

\section{Surveillance}

Strengthening surveillance is given particular priority in the CMO's strategy. The Communicable Disease Surveillance Centre's (CDSC) role is re-emphasised as the national focal point for coordination, analysis, and reporting from the varied systems of infectious disease surveillance, ${ }^{131}$ at national level, and through its units in all regions and the devolved administrations (apart from Scotland). In England these units support the Regional Directors for Public Health who are responsible for health protection. ${ }^{18}$ CDSC will serve to integrate other data which are relevant to the prevention and control of human infectious diseases, for example those data from veterinary surveillance, environmental monitoring, behavioural surveillance, and antimicrobial prescribing patterns and trends. ${ }^{1}$ It will not undertake surveillance for chemical and radiological threats, but those who do will now be better able to share expertise with CDSC. Building on the strength of the example of the British Paediatric Surveillance Unit, the CMO envisages broadening the number and types of clinical staff required to report the occurrence of infectious diseases. ${ }^{132}$ A duty of care will also be placed on all microbiology laboratories to report for public health purposes. New elements of surveillance will be introduced to cover important, common infectious disease problems that are not well recorded currently, such as those primarily seen in primary care. Electronic communications will need to be strengthened and health protection networks developed within broader public health structures. ${ }^{4}$ The Strategy also envisages better use being made of diverse local data provided through Public Health Observatories.

\section{Public education and involvement}

The new Strategy must not be confined to clinical and public health services if it is to protect children's health. The CMO also emphasises the importance of informing and involving the public (in tandem with that of involving health professionals). Good examples of how public education can be successful include early recognition of the meningococcal rash, increased use of breast feeding (in Scotland and Northern Ireland) and the uptake of interventions to prevent perinatal HIV infection. Further education campaigns will need to include issues ranging from overuse of antibiotics, to initiatives to protect young people from the effects of sexual ill health, smoking, excessive alcohol use, and acquiring hepatitis B and C and HIV through drug injecting.

\section{CLINICAL CARE_IMPROVING SERVICES FOR CHILDREN WITH INFECTIONS}

How will the CMO's Strategy and the NSF for Children deliver improved services for children with infections? The CMO divides effective management of commoner infections from the high quality management of special groups and serious infections. However, these should be seen as a continuum where management and referral pathways for infections are clearly delineated, from primary care (general practitioners, practice nurses, and NHS Direct) through general paediatricians to the tertiary specialist in infectious disease. The UK lags behind other Western countries in the paucity of paediatric infection specialists in centres of paediatric tertiary care. It is unacceptable that some children with serious infections still have to be treated in adult units because of lack of paediatric services. The setting up of clinical networks is an attractive option for achieving this and could be developed along the following lines.

\section{Clinical networks for infection}

Each acute trust would have a lead paediatric clinician (nurse or doctor), responsible for infection related issues. Such lead paediatricians would be involved in establishing local policies in both paediatrics and neonatology, for management of common infections, antibiotic protocols, and infection control. They would have to work with whoever led on immunisation performance in PCTs, Strategic Health Authorities, and the regional units of the HPA. ${ }^{18}$ The clinical lead could also take on the prime role in the clinical management of infection in immunocompromised children (whether as a result of cancer, or primary or secondary immunodeficiency). He or she would be supported by a major regional paediatric tertiary centre with the full range of paediatric services, including a specialist paediatric infectious disease service supporting a network of general acute trusts. Such networks are already developing in some regions-for example, Paediatric Oncology Shared Care Units and paediatric 
HIV services in London, facilitating the delivery of high quality care near the patient's home and the process of multidisciplinary audit. Formalising and extending these systems across the nation would have the potential for improving quality and equity of care for children. Specialist paediatric infectious diseases clinicians in turn would work as part of tertiary "infection centres", with specialist adult infectius disease, microbiology, and virology services. The CMO's Strategy acknowledges that training and continuing professional development programmes for paediatricians specialising in infection would need to be strengthened to meet these developments with tertiary centres playing a key role in the latter.

Are there obstacles to such developments? Setting up networks of infection care would not need major resources. All tertiary children's centres would need to accept that infectious diseases expertise is an essential part of a comprehensive children's service (many of the UK's units have already done this). At secondary care level, with acceptance of the CMO's strategy in the NSF new consultant posts and replacement appointments could be earmarked for those with an interest and training in infectious diseases. Alternatively existing consultants or clinical nurse specialists could undergo training to take on this role. Traditionally general paediatricians have seen the management of infection as being the "bread and butter" of their work. As part of infection networks most infectious disease in children needing secondary level care would continue to be managed by general paediatricians but they would be supported by their local lead colleague for infection and by the tertiary centres. This would enhance quality of care as well as providing a framework for continuing education and much needed research into common infections. Clinical microbiologists and health protection (public health) specialists would be an integral part of this development. Microbiologists are becoming increasingly involved in supporting clinical care through combined ward rounds and collaborative research and teaching programmes. The establishment of combined training programmes for doctors in microbiology and paediatrics is being actively considered. Virology and reference services would need to be strengthened. Some paediatricians in training already get public health experience through the PHLS/RCPCH Honorary Fellowships. Most paediatricians are also intuitive public health practitioners and this arrangement should increase and be supported financially. A recent initiative between the RCPCH and the Faculty of Public Health Medicine will increase the number of paediatricians who can gain such exposure during training. ${ }^{34}$

\section{CONCLUSION}

The Department of Health and others are developing detailed plans for the launch of the HPA in April 2003. The Strategy is however much more than just the Agency and will involve all parts of the National Health Service. It and the National Service Framework for Children should be welcomed by paediatricians as a unique opportunity to strengthen local and national health protection structures, and develop world class infection and health protection services for children.

\section{Arch Dis Child 2003;88:1-3}

\section{Authors' affiliations}

E G Davies, Host Defence Unit, Great Ormond Street Hospital, London, UK

M Sharland, Paediatric Infectious Diseases Unit, St George's Hospital, London, UK A Nicoll, PHLS Communicable Disease Surveillance Centre, London, UK

Correspondence to: Dr A Nicoll, PHLS Communicable Disease Surveillance Centre, 61 Colindale Avenue, London NW9 5EQ, UK anicoll@phls.org.uk

\section{REFERENCES}

1 Department of Health. Getting ahead of the curve. London: Department of Health, 2002 (http://www.doh.gov.uk/cmo/idstrategy/ idstrategy2002.pdf)

2 Department of Health. The Children's National Service Framework. London: Department of Health, March 2002 (www.doh.gov.uk/nsf/children.htm)

3 Nicoll A, Hamers F. Are trends in gonorrhoea, syphilis and HIV worsening in Western Europe? BM 2002;324: 1324-7 (http://bmi.com/cgi/reprint/324/7349/ 1324.pdf).

4 Atkinson P, Taylor $\mathrm{H}$, Sharland $M$, et al. Resurgence of paediatric tuberculosis in London. Arch Dis Child 2002;86:264-5.

5 Reacher $\mathbf{M H}$, Shah A, Livermore DM, et al. Bacteraemia and antibiotic resistance of its pathogens reported in England and Wales between 1990 and 1998: trend analysis. BM 2000;320:213-16.

6 Public Health Laboratory Service Laboratory. Confirmed cases of measles, mumps and rubella, England and Wales: January to March 2002. CDR, 27 June 2002 (http://www.phls.co.uk/publications/cdr/ pages/immunisation.html).

7 Jacobson JL, Jacobson SW. Postnatal exposure to PCBs and childhood development. Lancet 2001;358:1568-9.

8 Brown P. A view from the media on vaccine safety. Bull World Health Organ 2000;78:216-17.

9 Nicoll A, Murray V. Health protection-a strategy and a national agency. Public Health 2002; 1 16:1-9.

10 MacLehose L, Brand $\mathrm{H}$, Camaroni l, et al. BM 2001;323:861-3 (http://bmi.com/cgi/ reprint/323/7317/861.pdf).

11 Harling R, Twisselmann B, Asgari-Jirhandeh $\mathrm{N}$, et al, for the Deliberate Release Teams. Deliberate release of biological agents: initial lessons for Europe from events in the United States. Eurosurveillance 2001;6: 166-71.

12 Fleming DM, Smith, GE, Charlton, JRH, et al. Impact of infections on primary care-greater than expected. Commun Dis Public Health 2002;5:7-12

13 Nicoll A, Williams A. Breastfeeding. Arch Dis Child 2002;87:91-2.

14 National Audit Office, Department of Health. Meningitis $C$ campaign in modern policy making-ensuring policy making delivers value for money. London: National Audit Office, November 2001 (http://www.nao.gov.uk/publications/ nao reports/01-02/0102289.pdf).

15 Brown P. A view from the media on vaccine safety. Bull World Health Organ 2000;78:216-17.

16 Miller E, Waight $P$, Farrington $P$. Safety assessment post-licensure. In: Plotkin S, Brown F, Horaud F, eds. Preclinical and clinical development of new vaccines. Dev Biol Stand Basel Karger 1998:95:235-43.

17 Hutchison T, Nicoll A, Polnay L, et al. A training procedure for immunisation. Health Trends 1987; 19:19-23.

18 Department of Health. Shifting the balance of power, securing delivery. London: Department of Health, July 2001 (http://www.doh.gov.uk/shiftingthebalance/ shiftingthebalance.pdf).

19 Nicoll A, Elliman D, Begg NT. Immunisation: causes of failure and strategies and tactics for success (review). BM 1989;299:808-12.

20 Royal College of Paediatrics and Child Health. Working Party Report. Immunisation of the immunocompromised child; Best Practice Statement. 2002 (www.rcpch.ac.uk).

21 Department of Health. Screening of women for hepatitis B and immunising babies at risk. Health Services Circular July 1998 (http://www.nsc.nhs.uk/pdfs/hsc98127.pdf)

22 Department of Health. Reducing mother to baby transmission of HIV (HSC 1999/183). Health Services Circular. London: NHS Executive, 13 August 1999 (http://www.nsc.nhs.uk/pdfs/hsc99183.pdf)

23 Connor NC, Roberts J, Nicoll A, with the $\mathrm{PHLS}$ syphilis working group. Strategic options for antenatal screening for syphilis. J Med Screen 2000;7:7-13.

24 PHLS. Monitoring of antenatal screening for HIV in the UK. CDR 2002 12: No 17 (http//www.phls.org.uk/publications/cdr/ archive02/News/news 1702.htm)

25 Schuchat A, Neonatal group B streptococcal disease - screening and prevention. N Engl J Med 2000;343:208-10.

26 Nicoll A. Imported infections in children: epidemiological and public health perspectives. In: Hart CAH, Smyth RL, Duerden $\mathrm{BI}$, eds. Infections in children. J Med Microbiol 1998;47:947-55.

27 Williams JP, Chitre M, Sharland M Increasing Plasmodium falciparum malaria in southwest London: a 25 year observational study. Arch Dis Child 2002;86:428-30.

28 Booy R, Habibi P, Nadel S, et al and the Meningococcal Research Group. Reduction in case fatality rate from meningococcal disease associated with improved healthcare delivery Arch Dis Child 2001;85:386-90.

29 Department of Health. National strategy for sexual health and HIV. London: Department of Health, July 2001 (http://www.doh.gov.uk/ nshs/bettersexualhealth.pdf)

30 Johnson AM, Mercer $\mathrm{CH}$, Erens B, et al Sexual behaviour in Britain: partnerships, practices and HIV risk behaviours. Lance 2001;358: 1835-42.

31 Department of Health and Social Security Health Service Development. Co-ordination of epidemiological services for communicable diseases and food poisoning. Communicable Disease Surveillance Centre. Health Circular $\mathrm{HC}(80) 2$, LAC (80) 1. London: DHSS, February 1980

32 Nicoll A, Lynn R, Rahi J, et al. Public health outputs from the British Paediatric Surveillance Unit and similar clinician-based systems. J R Soc Med 2000; 93:580-5.

33 Department of Health. Drug use, smoking and drinking among young people in England in 2001: preliminary results (http://www.doh.gov.uk/public/ press 15 march02. htm)

34 Royal College of Paediatrics and Child Health. The next ten years; educating paediatricians for new roles in the $21 \mathrm{st}$ century. January 2002 (www.rcpch.ac.uk). 